\title{
Daylighting Performance of Various Layout Alternatives in an Open Building Apartment in Surabaya
}

\author{
M.L. Hendrik ${ }^{1}$, Asri Dinapradipta ${ }^{1}$, S.N.N. Ekasiwi ${ }^{1}$
}

\begin{abstract}
Utilization of natural light in an open building apartment is one of the several ways to save energy. Not only saving energy but it also sustains the healthy life of the occupants. This paper discusses the effect of layout alternatives mainly due to the potential changing arrangement of the bedrooms and the position of transparent window surfaces on daylighting performance i.e illuminance distribution and averages of illuminance. The Method used in this paper is an experimental method using Radiance 1.02 simulation as a tool. The changed layout in which is the bedroom spaces position concentrated on one window side of space with two separated transparent windows provides a good result with a percentage of area fulfills the standards equals to $29 \%$.
\end{abstract}

Keywords—Daylighting, Apartment, Open Building, Humid Tropic Climate, Layout.

\section{INTRODUCTION}

Open building is a concept of building that has design idea where the users can act as professionals in making design decisions. This design is a fixed design that cannot be changed by the users, while infill (fit-out level), is a part where the user can freely change and determine the interior of the building and determine also the extent of flexible space layout in accordance to their needs [1].

In the frame of the concept of an open building, occupants are allowed to change the space layout as needed. Problem of daylighting may arise when space gets deeper and more partitions are given. Arjmandi investigates the residential building of an apartment in Iran, the result shows that the amount of light is reduced in the inner space due to the limited space and window area [2]. Lee Ji-Eun and Lee Kang Up investigate that WWR must be different in every dwelling to be able to create a similar daylight environment [3].

Concurrent with that, the paper tries to see the daylight performance of these layout variations with some considerations i.e: the configuration of space and the position of the transparent window area. Several literature studies were used in this study for finding out the variation of alternative layouts and position of windows on the facade. Then, these several layout alternatives found were

\footnotetext{
${ }^{1}$ M.L. Hendrik, Asri Dinapradipta, Sri Nastiti N. Ekasiwi are with Department of Architecture Faculty of Civil Engineering and Planning, Institut Teknologi Sepuluh Nopember (ITS), Kampus ITS Sukolilo, Surabaya 60111, Indonesia. E-mail: mariahendrik.mh@gmail.com; asdina_p@arch.its.ac.id; nastiti@arch.its.ac.id.
}

simulated in order to see the effect of these on daylighting performance.

\section{METHODS}

The method used in this research is an experimental method. Radiance 1.02 simulation program was used to calculate daylighting performance. The building modeling was done using Ecotect Analysis 2011 program. This research used a base case model of an open building model which already exists. That is a next21 apartment in Japan. One of the apartment units in the Next21 building was chosen to represent an apartment unit in Surabaya. That was a unit of 302, which has 2:1 in ratio, and has transparent windows located on one side of the facade (figure 1).

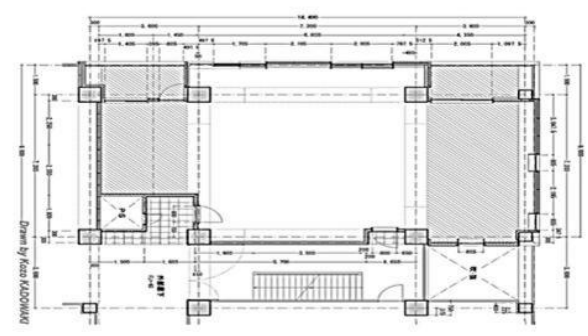

Figure 1. Next21 Apartment Layout

The simulation time is set in December and October, where the sky conditions in December tend to be cloudy, and in October the conditions of the sky are clear. The timing of the simulation is based on the estimation of the occurrence of the sky conditions, where the possibility of $0 \%$ sunshine occurs when the sun $0 \%$ of sunlight, and sky $0 \%$ cloudy when the solar radiation is $100 \%$. The material of the apartment space modeling is determined in accordance with subchapter 2.2.5, where according to Lechner finishing with high reflectance value can provide good light penetration and distribution. Therefore, the material with high reflectance in sequence are:

TABEL 1.

HigH REFLECTANCE MATERIAL

\begin{tabular}{|c|c|c|c|c|c|}
\hline No & Element & Color & Material & Reflect. & $\begin{array}{l}\text { VT (Visible } \\
\text { Transmittan) }\end{array}$ \\
\hline 1 & Ceiling & White & $\begin{array}{l}\text { Suspended concrete } \\
\text { ceiling }\end{array}$ & $80 \%$ & 0 \\
\hline 2 & Wall & White & Concrete block plaster & $70 \%$ & 0 \\
\hline 3 & Floor & White & $\begin{array}{l}\text { ConcFloor_tiles_Suspen } \\
\text { ded }\end{array}$ & $80 \%$ & 0.75 \\
\hline 4 & Glass & White & Singleglazed_alumframe & $70 \%$ & \\
\hline
\end{tabular}




\section{RESULTS AND DISCUSSION}

From the analysis of space layout on apartment precedents in Surabaya, and by categorizing these based on the pattern of spatial relationship, zoning, and activity, and space that mostly needs natural light (ie. The bedrooms), two variations of layout were suggested. These were two variations with two bedrooms (A2 and A3 models) and three positions of transparent windows, i.e one window, two separated windows, and three separated windows with WWR of $20 \%$ (figure 2 ).

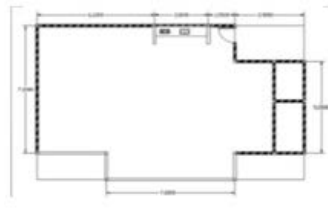

$\mathrm{BC}$

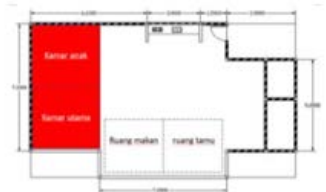

A2

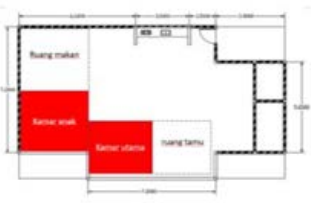

A3

Figure 2. Layout Variations

The pattern of variation A2, the pattern of the layout meets the criteria of the pattern of spatial relations, where the order of space that is, entrance, kitchen, living room, dining room and bedroom, while the criteria for light needs meet the criteria for the bedroom and living room. Therefore, this pattern will be used in the simulation.

Pattern of A3 variation, layout pattern fulfilling criteria of spatial relationship pattern, where the arrangement of the room is, entrance, kitchen, dining room, bedroom, dining room, while for criteria of light need fulfill criteria for bedroom and living room. Therefore, this pattern will be used in the simulation.

The design of the transparent plane on the facade is based on the general shape of the transparent area of the apartment, which is a rectangle. The vertical transparent plane positions are divided into 3 models: 1 transparent, 2 transparent and 3 transparent, each with 20\% WFR. The three transparent field models are then combined with layout variation to be simulated (figure 3). There are six combination based on the result combination of layout and transparent field. The combination for A2 variation are 3 combinations, A2x, A2y, A2z, and 3 combinations for A3 variation, A3x, A3y, A3z.

\section{A. Simulation Analysis}

Analysis of the distribution of daylight in space was done by comparing the level of illumination at each point of measurement in space. The illumination distribution in each variation will be compared with the illuminant standard, to find out the percentage which appropriate to the room standard, and which percentage does not match the standard. The illuminant distribution is analyzed by the simulation, in each variation and each position of the transparent field, and then compared with the base case. The measuring point on the spatial plan, divided into 9 points located $1.5 \mathrm{~m}$ from the wall adjacent to the transparent plane, and 8 points $1 \mathrm{~m}$ away from the transparent plane, as shown in Figure 3.

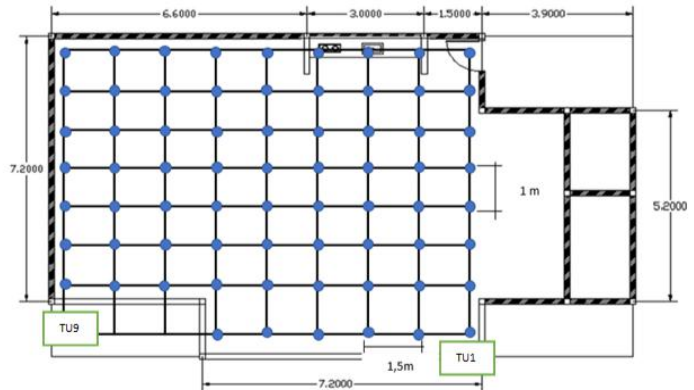

Figure 2. Points of Measurement

The position of the measuring point in sequence from right to left, given notation 1 - 9 while the position of the measuring point from the transparent field, to the rear in the notation based on the distance from the transparent field starting from the point 0 - 8 meters from the transparent field.

\section{B. Result of Base Case Simulation}

The average illumination in the base case with different transparent field conditions indicates a decrease in illumination in $\mathrm{BCx}, \mathrm{BCy}, \mathrm{BCz}$ with the greatest decrease in October simulation, up to 55 lux between $\mathrm{BCx}$ and $\mathrm{BCz}$ conditions (figure 4).

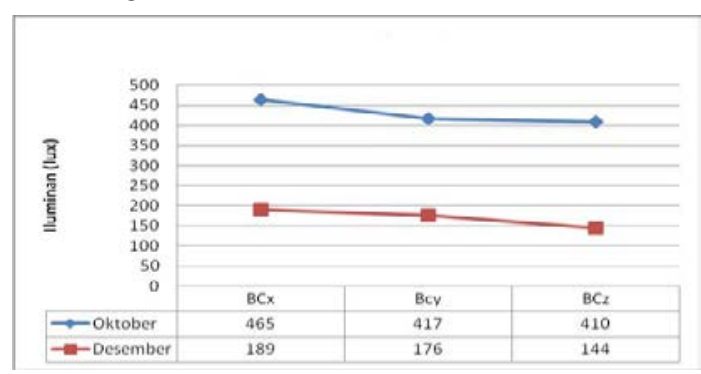

Figure 3. Average Illuminant in Base Case

Based on the graph above, it is known that the average illumination in the base case with the transparent field conditions of $\mathrm{x}, \mathrm{y}$, and $\mathrm{z}$ in the October simulation has a higher illuminance value than December, this is because the sky conditions in October are brighter than in the December, where the sky condition is cloudy sky. Isokontur graph above shows the 1 transparent field condition, the illuminant value at point 0 has the highest illumination value, but decreases to 600 lux at a distance of 2 meters and up to a distance of 8 meters from the transparent field, this is in accordance with the theory conveyed By Ander, where Ander states that the depth of space has a direct effect on the intensity of the illumination of natural light from sidelighting.

The illumination distribution in the base case with the transparent field condition $y$, having a more even distribution at the side measuring point as to reduce the glare, this is in accordance with the theory presented by Lechner (2009), ie openings scattered on one wall can reduce glare in comparison with aperture concentrated in one position. The highest illuminant value in the base case on October simulation $\mathrm{x}$ is 4024 lux on the measuring tier 2 
with a distance of 0 from the transparent plane, and the lowest of 95 lux at the point 2 with a distance of 8 meters from the transparent plane. The area that meets the standard is $35 \%$ and that does not meet the standard that is equal to 65. The highest illuminant value in the base case y is 1064 lux at the measuring point 5 with a distance of 1 meter from the transparent plane, and the lowest 79 lux at the point 2 with a distance of 8 meters from the transparent plane. For areas that meet the standard that is $41 \%$ and that does not meet the standard 59\%. The highest illuminant value of Base case $\mathrm{z}$ is 2897 lux at the measuring point 5 with a distance of 0 meters from the transparent plane, and the lowest 79 lux at the measuring point 2 with a distance of 8 meters from the transparent plane. The area that meets the standard is $39 \%$ and the area does not meet the standard is $61 \%$.

December simulation results above shows the illumination distribution in the base case is much different from October. In the transparent field, condition y has a more even distribution on the side measuring point as to reduce glare, this is in accordance with the theory presented Lechner, openings spread on one wall can reduce glare. But in the December simulation, natural light conditions were lower than in October.

The highest illuminant value in the base case $\mathrm{x}$ is 1303 lux on the measuring tier 5 with a distance of 0 from the transparent plane, and the lowest 54 lux at the point 2 with a distance of 8 meters from the transparent plane. In the base case $y$, the highest illuminant value is 403 lux at the point 1 with a distance of 0 meters from the transparent plane, and the lowest is 52 lux at the measuring point 2 with a distance of 8 meters from the transparent plane. The appropriate area standard on the transparent field $\mathrm{x}$ condition, on December 15th, is $52 \%$ and the area does not meet the standard is $48 \%$. Meanwhile, on the condition of the transparent field $\mathrm{y}$, the appropriate area standard on December is $40 \%$ and the standard does not match is $60 \%$. While in the transparent zone $\mathrm{z}$ condition, the appropriate standard area is $31 \%$ in December, an area that does not meet the standard is equal to $69 \%$. This shows the simulation results based on different sky conditions indicating, the area that gets natural light, has the same percentage. When the sky is cloudy, the percentage of area that meets standard is larger than the bright sky, due to in October the exposure time longer than December, so it is possible to occur an overbright in the space.

\section{Comparison of each Variation Illuminant distribution of A2 Variation}

The illuminant distribution of the variation of A2 with the transparent conditions of $\mathrm{x}$ and $\mathrm{y}$ in December is as shown in Figure 4.11. Based on the iso-contour graph below, the A2x variation has a different contour pattern at each measurement point, where at point 2 is 1594 lux, the point 5 is 1653 lux, and the point 8 is 1704 lux. The value of the illumination at a point on the transparent plane area is uneven, because of the contrast in the measuring point area having a lower illuminant value, this phenomenon is due to the position of the transparent plane on the wall

concentrated at one point so that the light is not evenly distributed.

In the A2y variation, the illuminance at the measuring point with a distance of 0 meters has an evenly uniform value, this condition can reduce glare in the transparent area. This is in accordance with the theory presented by Lechner (2009), which states that the position of the transparent field is scattered, better than the transparent plane concentrated at one point. In the transparent position of $\mathrm{z}$, the distribution graph at the measuring point shows the same pattern as the A2x variation, the illumination value at 0 meters distance from the highest transparent plane at the measuring point 2 is 880 lux, at the point 5 of 920 lux, and the 8 point of 890 Lux, the illumination value on the $\mathrm{A} 2 \mathrm{z}$ variation is lower than $\mathrm{A} 2 \mathrm{x}$.

The illumination distribution conditions in the graph above show the same decline on December 15th, but the illumination at different points is different. The illumination on October 15th is higher than on December 15th. On the A2x variation the highest illumination reached 4001 lux, and on the highest A2y illuminant variation reached 1007 lux, while at the highest A2z of illumination reached 2732 lux. This phenomenon occurs because in October, the long sun exposure is longer, and the condition of the sky tends to overcast, where in this condition, the sky is covered by a thin cloud, so the light of the sky becomes more extreme in the room.

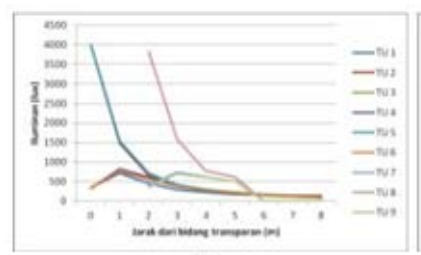

$\mathrm{X}$

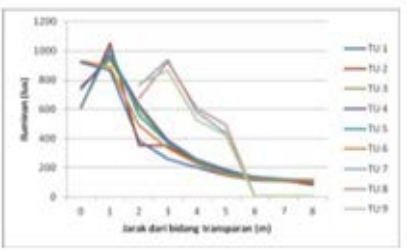

y

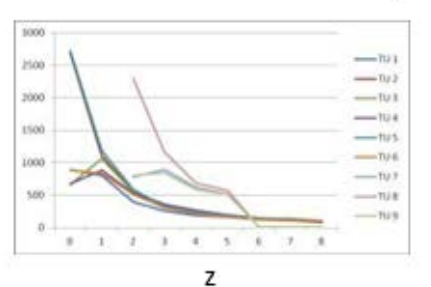

Figure 4. Iluminant Distribution of A2 Variation with different transaparent field

\section{Illuminant Distribution of A3 Variation}

The illuminant distribution on the A3 variation with the transparent field conditions $\mathrm{x}, \mathrm{y}$ and $\mathrm{z}$ on December 15th, can be seen in figure 4.13. In the A3 variation, the illuminant distribution is not evenly distributed throughout the room, this is due to the bulkhead in the master bedroom and the child's bedroom, so the light is not well distributed to the deepest of the area. At the point of measurement 1 3 , the illumination distribution to the back area reaches 60 30 lux, but at the point of measurement 4-9 the illumination at the rear area becomes lower between $16-70$ lux as blocked by the partition, and the light in this area comes from light reflected from the living room area, this is in accordance with the theory presented by Lechner. 


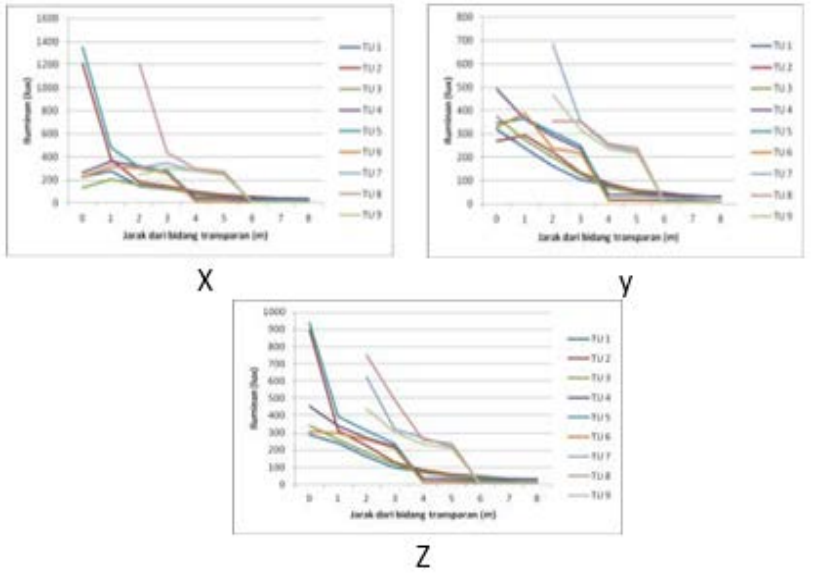

Figure 5. Iluminant Distribution of A2 Variation with different transaparent field

Based on the isocontour graph as shown in figure (..), the A3x variation has a different isocontour graphic pattern in each point, the highest illuminant is at the measuring point 5 at a distance of 0 from the transparent plane of 1350 lux, while the lowest illuminant is at point 9 with at a distance of $8 \mathrm{~m}$ from the transparent plane of 6 lux. The isocontour graph of the A3y variation, indicating the area close to the transparent area is more evenly distributed, this is due to the position of the transparent plane which is placed on the wall so that the area near the transparent field has an evenly distributed illumination. The highest illumination in this variation is at point 7 at distance 0 of the transparent area of 684 lux, and the lowest at point 9 at a distance of 6 meters from the transparent plane of 5 lux.

\section{E. Effect of Layout Change and Position of Transparent Field}

Based on the discussion of the natural lighting performance of both the illumination distribution and the average illuminant in the previous sub-section, the effect of the layout changes on the illuminant distribution, the average of the illuminant, and the percentage of areas that meet the natural lighting standards at residential, and which do not meet the standard (too bright / overbright or too dark) is described as follows.

The layout changes have a considerable influence on the illuminant distribution, where the change of the base case conditions under $\mathrm{A} 2 \mathrm{x}$ variation with the position of the bedroom is on one side of the space and the transparent position of the 1 field is concentrated in one area of transparent field, causing the decrease of the percentage of area that satisfies standard by $8 \%$ from $35 \%$ to $27 \%$ in October, and by $23 \%$ from $52 \%$ to $29 \%$ in December. In the A2y variation, the position of the transparent area is scattered on the facade, causing a decrease in the percentage of areas that meet the standards of the base case conditions by $16 \%$ from $40 \%$ to $24 \%$ in December and by $14 \%$ in October from $41 \%$ to $27 \%$. While the change in the position of the transparent 3-field field led to a decrease in the percentage of areas that meet the standards of $6 \%$ in December from $31 \%$ to $25 \%$ and decreased by $14 \%$ from $39 \%$ to $25 \%$ in October.
Changing the position of the space with a concentrated position on the area close to the transparent plane (Variation A3) causes the distribution of light cannot reach the deepest area, due to blocking the space, this causes the average illumination in this variation decreases, and affect the percentage of area which is meet the standard. In the A3x variation model in December the percentage of the standard meeting area was only $16 \%$, where there was a $36 \%$ decline of the base case $52 \%$ while in October the percentage of the standard meeting area was $11 \%$ of the $35 \%$ base case condition. In the case of 2 transparent areas (A3y variations) in December decreased by $20 \%$ from base case $40 \%$ to $20 \%$, while in October the decreased from base case condition occurred by $33 \%$ from $41 \%$ to $8 \%$. In the three transparent conditions, the position of the area of decrease of the percentage of area that meets the standard from the base case condition is $14 \%$ from $31 \%$ to $17 \%$. This result makes the condition of A3 variation as a variation with poor lighting conditions compared to other variations.

\section{CONCLUSION}

The results of this study are the variations of layout and transparent field positioning that can be applied to open building and explain the consequences of each of the best variation categories according to the performance of natural lighting, viewed by the illuminant distribution, and the average illuminant. Based on the results of the discussion in the previous chapter, it can be concluded:1. The possibility of layout and transparent variation on the facade, related to the quality of natural lighting in open building concept, is determined based on the category of spatial relations relations, zoning, and areas most in need of light, namely: To arrange two bedroom apartments, there are 2 best variations: bedroom position are placed on one side of the room, with one transparent area (Variation A2), and the position of the bedroom is spread across the transparent area (variation A3).

The consequences of each category of layout and transparent variation on natural lighting performance are: Change of layout and position of transparent field, from base case condition, causing change of illuminant distribution, average of illuminant, and percentage of area according to standard, quite significant.

There is a decrease in the average illuminant from the base case condition to variations with spatial position spread, due to the change of layout resulting in changes in the distribution of the illuminant, and affecting the average of the illuminant. However, the average of an illuminant on the A2 variation has met the standard in December simulation, so this variation is quite good compared to other variations. The percentage of the area that meets the standard has decreased from the base case condition which reaches $50 \%$ until the A3 variation is only $7 \%$ of the area that meets the standard, the more space, and the more space that divide by a partition, the decrease of the percentage of the space that meets the standard. 
The $3^{\text {rd }}$ International Seminar on Science and Technology

August $3^{\text {rd }}$ 2017, Postgraduate Program Institut Teknologi Sepuluh Nopember, Surabaya, Indonesia

\section{REFERENCES}

[1] S. Kendall and J. Teicher, Residential open building. London: E \& FN Spon, 2000.

[2] H. Arjmandi, M. M. Tahir, M. M. Shabani, A. I. Che-Ani, N. A. G. Abdullah, and I. M. S. Usman, "Application of Transparency to Increase Day-Lighting Level of Interior Spaces of Dwellings in Tehran -A Lesson from the Past," in Selected Topics In Power
Systems And Remote Sensing, H. Fujita and J. Sasaki, Eds. Iwate, Japan: World Scientific and Engineering Academy and Society, 2010, pp. 297-307.

[3] J. Eun Lee and K. Up Lee, "The Study on the Elevation Design of Apartments Incorporating Daylight Performance," Int. J. Eng. Technol., vol. 6, no. 1, pp. 70-75, 2014. 